\title{
Ana Loforte: história viva de um legado à Antropologia e aos estudos de gênero em Moçambique
}

Dol

http://dx.doi.org/10.11606/ 2179-0892.ra.2019.168626

ENTREVISTADORES

Vera Gasparetto https://orcid.org/ 0000-0002-3865-0549 Helder Pires Amâncio https://orcid.org/00000001-6726-2169
History Of A Legacy To Anthropology And Cender Studies In Mozambique

Ana Loforte:
Entrevista ${ }^{1}$ com

Ana Maria Loforte (AL) 


\section{Professora Ana, gostaríamos primeiramente de saber sobre sua trajetória, sua convivência familiar e sobre eventos que marcaram e influenciaram sua vida e suas escolhas.}

AL | Certo! Bom eu sou a quarta de quatro irmãos: somos três mulheres e um homem que é o mais velho. Infelizmente no período que eu nasci a vida estava difícil para a minha família, para o meu pai que estava desempregado. Então, foi muitas vezes a minha mãe - que no âmbito das próprias estratégias de sobrevivência que as mulheres desenvolviam para fazer face ao dia-a-dia, aos problemas, fazia negócios, fazia bolos para vender. À determinada altura o meu pai foi para uma tentativa de emprego no Xai-Xai ${ }^{3}$ e mandava determinados produtos que na província onde eu nasci, Inhambane, careciam e era muitas vezes o negócio

3 | Capital da província de Gaza - Sul de Moçambique. que a minha mãe fazia que permitia que tivéssemos al guma renda para a compra de produtos alimentares e podermos pagar nossos estudos.

Portanto, os primeiros anos da infância foram muito difíceis, de muita batalha e foi a inspiração que eu tive desta luta desenvolvida pela minha mãe que me levou anos mais tarde, talvez ainda não muito consciente, a valorizar a contribuição das mulheres para a economia familiar e a luta que elas desenvolvem no dia-a-dia para criar os filhos. Isto foi no período que eu tinha cerca de 11 anos. Depois o meu pai conseguiu um emprego na cidade de Maputo (na altura chamada Lourenço Marques) e eu, os meus irmãos viemos viver juntos e as coisas melhoraram um pouco. Os meus pais sempre incentivaram todos os filhos a estudar, mesmo que não tivessem tido muitos estudos, mas o meu pai dizia-nos sempre que o mais importante era estudarmos, fazer o curso para que pudéssemos brilhar na vida. Então foi isso! O meu irmão mais velho frequentou o ensino superior, depois não concluiu por que decidiu que queria casar, ter filhos, contra a vontade dos meus pais. As minhas outras irmãs ficaram ao nível secundário e eu fui a pessoa que teve a oportunidade e o apoio dos pais para ingressar no Ensino Superior e ter uma carreira acadêmica. Sempre com muito incentivo, apoio, elogio por parte da minha família, que de fato considerava que estudar era o mais importante na vida, ainda que sendo uma mulher e que naquele momento, bem antes da independência, havia a ideia de que o lugar da mulher é em casa: se preparar é para ficar em casa, ser uma boa esposa, ser uma boa mãe. Mas eu tive este ambiente que incentivava a formação, considerando que era a porta de entrada para uma vida melhor.

\section{E, desta forma como é que foi que a senhora escolheu a Antropologia ou como é que a Antropologia Ihe escolheu?}

AL | Eu fiz uma formação em História e a possibilidade de fazer um Bacharelado em História que concluí em 1974/75. Depois disso era o período da independência e um grupo de alunos do curso de História - eu, Teresa Cruz e Silva e outros 
colegas (alguns ainda aqui, outros em Portugal) - recebemos um convite para sermos investigadores/as do Centro de Estudos Africanos (CEA), no mesmo edifício onde funcionavam outros departamentos, como Ciências Humanas e Ciências da Terra. Num desses departamentos trabalhava uma etnóloga portuguesa, a doutora Maria Helena Corrêa de Mattos, que tem uma série de trabalhos sobre populações chopes ${ }^{4}$ aqui do Sul de Moçambique. Ela fazia trabalho de campo e considerava importante integrar alguns investigadores moçambicanos na tarefa do trabalho de campo. Convidou-me para trabalhar com ela na província de Inhambane, onde ela fazia recolha de tradições orais e desenvolvia etnografia. Foi através desse convite que me iniciei nestes estudos sobre os aspectos culturais, as questões da tradição oral, mais ligada à história dos povos de Moçambique. Passados dois anos, ela partiu para Portugal e deixou em mim esta curiosidade de fazer trabalho de campo e conhecer um pouco mais sobre as tradições culturais, sobre os modos de vida das populações. Depois eu quis continuar os meus estudos, quis fazer a licenciatura, e para isso tinha que desenvolver um trabalho de campo e fazer uma monografia. $\mathrm{Na}$ sequência surgiu a oportunidade de fazer uma especialização na Universidade de Paris 8, mais ligada à Antropologia. Fiz o trabalho de campo na zona norte de Inhambane, sobre a migração dos trabalhadores moçambicanos para as minas da África do Sul e o impacto que isto tinha sobre as mulheres. As mulheres que ficavam em Moçambique e que tinham sobre as costas toda uma série de atividades, desde a educação dos seus próprios filhos, a tomada de decisões no dia-a-dia sem a presença do marido. Também a utilização de toda uma série de bens que estes migrantes mandavam ou traziam quando vinham de férias e que influência isto tinha no modo de vida das mulheres. Esses foram os primeiros trabalhos mais de caráter etnográfico, que desenvolvi influenciada pelo que aprendi com a Dra. Maria Helena.

Professora, nesse contexto o que lhe levou a pesquisar sobre a migração desses homens e o impacto no modo de vida das mulheres? E a escolher Inhambane tendo em conta que nasceu lá?

AL $\mid$ Bom, dois motivos: Por um lado Inhambane é a província onde eu nasci e conhecia. Entendia, embora não fluentemente, mas falava a língua, portanto, era fácil dialogar com os meus informantes. Por outro lado, a segunda influência que eu tive foi do antropólogo Christian Ceffray (que nos anos 1980 veio trabalhar em Moçambique), quando fizemos conjuntamente um trabalho de campo em Vilanculos, no mesmo local. E, por que os migrantes? Por um lado, este trabalho inicialmente nem era sobre processos migratórios, mas verificamos que havia uma influência muito marcante de ausência dos homens nos agregados familiares e todo um desenvolvimento de estratégias de sobrevivência diária por parte
4 | Grupo étnico da região Sul de Moçambique. Os Vacopi no plural ou Copi no singular, como corretamente se escreve na língua Bantu, segundo Mudiue (2005: 10) "fazem parte dos povos que outrora se deslocaram do reino de MweneMutapa e emigraram para o sul, vindo fixar-se onde hoje são os distritos de Chibuto, Mandlakazy, Xai-Xai, Zavala, Inharrime, Panda e Homoíne". Ainda de acordo com este autor, este grupo/povo possui uma língua genuína, uma cultura e constituição física particular. 
das mulheres para fazer face a ida dos homens para as minas da África do Sul. Do ponto de vista do próprio estatuto destas famílias notava-se uma diferenciação grande em relação àquelas famílias cujos chefes de agregados permaneciam no local, numa zona de atividade econômica pesqueira, com pouca prática da agricultura porque havia secas constantes, portanto, a vida dessas famílias era difícil. Aquelas famílias que conseguiam ter o rendimento proveniente dos migrantes tinham em termos econômicos um estatuto mais elevado.

Foi dessa forma que os estudos de gênero foram entrando na sua trajetória acadêmica?

AL Exatamente, foi desta forma que os estudos de gênero entraram na minha trajetória. Bom, para além desses trabalhos eu participei num trabalho do CEA. Como disse, nós éramos antigos estudantes do professor Canhão, sobre o Mineiro Moçambicano, que foi o primeiro reitor da UEM depois da independência. Devido a esse estudo eu estive em Homoine, na província de Inhambane, onde obtive informação sobre a temática da Migração para a África do Sul. Estava interessada em ver o papel que as mulheres tinham a nível dos agregados familiares, no sistema de parentesco patrilinear, onde também é marcante a presença dos membros da família do marido, uma vez que as mulheres ao casarem vão viver junto a essa família. Observar que margem de manobra no dia-a-dia as mulheres tinham para tomar decisões, vivendo em agregados patrilocais, com forte presença da sogra, das cunhadas, como é que isto em termos das próprias relações de poder se manifestava e que influência tinha em termos de poder que pudesse ser exercido pelas próprias mulheres. Então pouco a pouco começou a surgir esta inquietação (risos), sobre as relações de poder ao nível da família, o papel das mulheres. Depois surgiram outras influências, outros estudos e trabalhos de consultoria. Trabalhei com a professora Isabel Casimiro em consultorias por parte da Organização da Mulher Moçambicana (OMM), que estava interessada em ter informações sobre a situação das mulheres em Moçambique, a situação econômica, uma série de trabalhos que formos desenvolvendo de investigação e de consultorias, numa altura em que se considerava importante ter maior conhecimento sobre estas matérias.

Nós encontramos no Arquivo Histórico muitos documentos desses trabalhos que a senhora refere sobre a $\mathrm{OMM}$, percebemos sua presença muito marcante, bem como da Isabel Casimiro já desde o início dos estudos de gênero, no pós-independência. Como é que você, olhando para sua trajetória, avalia a sua contribuição para o campo dos Estudos de Gênero em Moçambique?

AL | Bom, se eu quiser fazer uma avaliação eu poderei... (risos), sem dizer que é uma falsa modéstia digamos assim (risos), que acabamos sendo as pioneiras, 
não é? Eu, a Isabel e outras colegas que realizaram esses mesmos estudos. Conseguimos pelo menos trazer aos de cima, dar visibilidade ao papel desempenhado pelas mulheres ao nível das famílias, porque havia a percepção de que as mulheres deviam participar no desenvolvimento do país. Este era o slogan do dia-a-dia e transmitia a ideia de que a contribuição que a mulher dava não era considerada uma participação grande a nível do desenvolvimento do país. Então a contribuição que demos com os resultados desses estudos, foi trazer muita informação de que a mulher participa neste desenvolvimento de forma bastante ativa. O que falta é um reconhecimento dessa participação, desse trabalho, não há uma partilha dos benefícios do próprio processo com as mulheres.

Muitas vezes o discurso ao nível do próprio partido, da própria FRELIMO, era de fato da emancipação e participação da mulher, que vinha desde a luta. Por um lado, não havia este reconhecimento e, por outro, em termos de partilha dos benefícios desta mesma participação, não existia o benefício para as mulheres. Penso que foi importante o que nós fizemos, como entrevistas com as mulheres das cooperativas na periferia da cidade de Maputo que nos forneceu muita informação sobre a participação destas mulheres na produção agrícola na periferia, que alimentava a cidade de Maputo e outras cidades. E como que essa presença das mulheres nas cooperativas permitia inclusive os estudos dos filhos, porque havia creches, havia escolinhas para as crianças. Como é que isto contribuía para a educação das crianças e a ocupação por parte da mulher de espaços que traziam alguma renda, algum benefício para a família. Embora fosse uma atividade agrícola que elas já exerciam e exercem, trazia outros tipos de proveitos e benefícios e uma certa liderança por parte das mulheres.

\section{Após a especialização em Paris, como se deu sua trajetória acadêmica?}

AL | Depois de fazer o que se chama maîtres em Paris, voltei à Moçambique e terminei o meu trabalho para concluir a licenciatura em História. Depois fui fazer especialização na área de Antropologia. Paralelo a isso a minha atividade principal - sobretudo naquela altura em que havia muita falta de docentes - foi a atividade de docência na área de história, na Faculdade de Letras. Também participei como docente numa primeira fase, acompanhando docentes estrangeiros, mas depois assumi a docência de cadeiras de Antropologia em vários cursos, porque começou a surgir uma demanda muito grande em termos da disciplina em diferentes universidades. Naquela altura havia universidades públicas, era a UEM, a Universidade Pedagógica, a Escola de Estado e Direito (que formava administradores) onde havia a cadeira de Antropologia Cultural. Também na Faculdade de Direito da UEM. Depois disso surgiu a licenciatura em Antropologia. 
Ao mesmo tempo eu me preparava para o doutoramento, o qual fiz uma parte letiva em Portugal, no Instituto Superior de Ciência, Trabalho e Empresas (ISCTE) e depois comecei a fazer o trabalho de campo aqui na cidade de Maputo. Foi um período de muitas restrições porque naquela altura era a guerra civil entre a RENAMO e a FRELIMO. Levei quatro anos e meio a fazer a recolha de informação e a elaboração da tese. Em certas ocasiões tinha que interromper porque a guerra estava aqui na cidade, havia dificuldades em chegar ao campo, às vezes ia um dia, marcava uma entrevista, no dia seguinte passava para entrevistar e não estavam as pessoas porque tinham se movimentado ou algum membro da família estava morto e as pessoas já não podiam falar. Foi um período muito, muito difícil para conseguir fazer a recoIha da informação, levou bastante tempo. A temática era sobre as questões de poder e gênero aqui na região sul de Moçambique, que era interessante do ponto de vista sociológico. Por causa da guerra havia uma pluralidade de situações nesta periferia da cidade, diferentes grupos étnicos provenientes da Zona Sul que vinham para a capital por razões de segurança e a procura de melhores condições. Havia uma miscelânea muito grande em termos de grupos que habitavam a periferia de Maputo, em função também desta situação de instabilidade, mas que por outro lado, permitia fazer a comparação entre os modos de vida diferenciados, a questão da adaptação ao meio urbano por parte destas populações que vinham de fora, as redes de solidariedade que se teciam no local para fazer face a situação de guerra, as dificuldades econômicas que as famílias enfrentavam e ainda a participação das mulheres, também, ao nível das cooperativas, produzindo bens de consumo para alimentar a cidade, numa altura de muitas carências.

Professora, surgem-me algumas curiosidades sobre Escola do Estado e Direito, a Faculdade de Letras até ao surgimento do curso de Antropologia. Poderia comentar essa relação da Antropologia com o processo de construção do Estado moçambicano? E como surge o Departamento e o curso de Antropologia, tendo em conta o relatório de 1987, sobre da importância dos estudos antropológicos, que em algum momento foram marginalizados. Por fim a transição do CEA (onde existiam alguns estudos) para o Departamento de Arqueologia e Antropologia (DAA)? Não sei se é muita coisa! (Riso)

AL | É muita coisa (risos). Vou situar do ponto de vista temporal. Nos primeiros anos da década de 1980 tivemos o primeiro seminário de Antropologia, com a presença de antropólogos estrangeiros: portugueses, franceses, a própria presença do Christian Geffray e de outros antropólogos britânicos. Eu lembro que houve intervenções sobre questões de Antropologia e Nutrição. Este seminário foi um marco na criação do DAA, porque a Arqueologia já existia, 
mas a componente antropológica surgiu depois dele. Foi um seminário com muito debate, muita polêmica, porque, alguns dos participantes não concordavam com a importância da Antropologia, devido sua associação ao colonialismo e à ciência colonial, que contribuíam para a opressão dos povos. Havia um investigador que dizia "pois é, estes antropólogos vêm para cá e tentam etnografar a população moçambicana". Havia uma crítica séria em relação à Antropologia, mas havia outros antropólogos que tentavam demonstrar com evidências concretas, sobretudo, em relação ao que aconteceu com as aldeias comunais, como as mesmas foram implantadas, sem ter em conta o modus vivendis da população, sem ter em conta o seu universo cultural, o apego que tinham em relação à terra, aos seus ancestrais que ali tinham sido enterrados. Portanto, uma série de erros que foram cometidos na implantação das aldeias comunais exatamente porque não se teve em conta estes aspectos da população.

Ali vincou a posição das pessoas que defendiam a necessidade de haver estudos antropológicos em Moçambique para o melhor conhecimento da população onde os projetos de desenvolvimento seriam implantados. Em 1982 surge então a componente antropológica que era inicialmente uma seção de Antropologia no Departamento que já existia. Devido a esta necessidade de melhor conhecimento, a própria escola de Estado e Direito, inspirada pela tradição colonial dos administradores, muitos deles eram antropólogos e tinham a necessidade de conhecimento sobre as populações nos locais onde exerciam a atividade de administração colonial. O próprio Jorge Dias é uma referência grande em termos do conhecimento sobre os Macondes 5 , para o qual a administração colonial encomendou esse estudo para melhorar sua penetração no território, melhorar o conhecimento desta população, numa altura em que estava surgindo a luta armada. A partir do debate reconheceu-se a necessidade de conhecer as populações que iriam administrar e governare, portanto, começou a surgir a Antropologia Cultural na Escola de Estado e Direito. Surgiram necessidades ou demandas dos Ministérios, também ligadas a projetos. Alguns estudos antropológicos foram feitos para a antiga Direção Nacional da Habitação, e tinham a ver com a implantação das Aldeias Comunais em diferentes zonas do país. Surgiram solicitações no âmbito da Antropologia da Saúde e depois, com o advento do HIV e SIDA a necessidade de melhor conhecimento sobre as concepções de saúde e doença por parte das populações. Era necessário saber como é que as populações interpretavam a causa das doenças e como é que se aplicaria determinados tipos de terapias, determinados tipos de itinerários terapêuticos. Para isso era necessário conhecer para garantir as formas de tratamento e abordagem das próprias populações e dos curandeiros, dos praticantes da medicina tradicional face ao HIV. Então começaram a surgir também,
5| São um povo da África Oriental, descendentes dos Bantu, que se fixaram numa zona a sul do Lago Niassa. "A hipótese desta origem é reforçada pela análise das semelhanças culturais com o povo Chewa, que ainda hoje habita uma vasta zona a sul e sudoeste do lago Niassa. Os Makonde teriam assim pertencido, em tempos remotos, a uma grande federação Marave, que teria iniciado a sua migração para nordeste, ao longo do vale do rio Lugenda em tempos bastante longínquos" (ROSEIRO, 2013, p.38). 
essas necessidades de ter antropólogos com algum tipo de conhecimento. Esta Antropologia do Desenvolvimento também impulsionou a diversificação das áreas de conhecimento no âmbito da Antropologia e trouxe a necessidade de haver este contato com outras escolas do pensamento antropológico e a que os poucos moçambicanos que se formavam pudessem se interessar e abraçar outras áreas científicas, no âmbito da própria Antropologia. É uma entre Antropologia do Desenvolvimento e Antropologia Aplicada.

\section{E o surgimento do curso de Antropologia, como é que foi esse processo!}

AL Pois, fruto desta demanda que eu referi, porque nós tínhamos Antropologia como uma cadeira nos diferentes cursos: no curso de Direito, no curso de Linguística, no curso de História.

\section{Ela era transversal, nas diferentes áreas.}

AL | Exato! Ela era transversal nas diferentes áreas e fruto desta demanda nós consideramos que era necessário ter uma formação mais sólida, por isso fizemos a proposta de criação de um curso de Antropologia que pudesse dar as ferramentas, aprofundar as questões teóricas e metodológicas da própria Antropologia. Para isso contamos com a colaboração de antropólogos brasileiros da Universidade de Campinas (UNICAMP) e da Universidade de São Paulo (USP), com quem a Faculdade de Letras tinha cooperação da Gulbenkian $^{6}$, de Portugal. Pelo período de três/quatro meses os antropólogos brasileiros vinham lecionar cadeiras nesta licenciatura. Também contamos muito com antropólogos portugueses, ao abrigo desta cooperação. Conseguimos que eles suprissem a falta de docentes no curso de Antropologia, que quando começou, o primeiro tinha 11 estudantes, felizmente eram muito bons e hoje são docentes no DAA. Na cooperação com a Fundação Ford, alguns estudantes moçambicanos foram fazer Antropologia e Sociologia no Brasil, como é o caso de Cristiano Matsinhe. Tivemos a possibilidade de ter alguns moçambicanos a fazer formação fora, que concluíram e puderam colaborar como docentes no curso de Antropologia. Foi assim que nos anos seguintes começamos a ter mais estudantes, mais interesse por parte dos moçambicanos, porque começaram a surgir muitas demandas. No início era raro ver um anúncio de jornal pedindo colaboração de um Antropólogo para trabalhar num Ministério ou numa ONG etc. Mas começaram a surgir possibilidades e daí o interesse das pessoas a fazer uma formação nesta área. Aqueles que concluíram a licenciatura em Antropologia, também no âmbito desta cooperação que nós tínhamos com Portugal e Brasil, seguiam para fazer o mestrado e depois doutoramento na área de Antropologia.
6|A Fundação Calouste Culbenkian é uma instituição portuguesa de direito privado e utilidade pública geral com caráter perpétuo, cujos fins estatutários são a Arte, a Beneficência, a Ciência e a Educação. Mais informações disponíveis em: https://gulbenkian.pt/ fundacao/o-que-somos/. 
Como é que esse processo contribuiu para constituir um campo de Antropologia em Moçambique na atualidade? E quais seriam os grandes desafios para esse campo?

AL Bom, os desafios são muitos, nós fizemos esse esforço inicial com poucos recursos locais. Contamos muito com a colaboração externa, conseguimos com muito sacrifício levar a cabo este curso de Antropologia. O grande desafio que se colocava, e ainda se coloca, apesar de há alguns anos estar um pouco afastada, é relativo às condições de trabalho criadas para estes docentes, alguns dos quais fizeram uma formação não só em Moçambique, como puderam aprofundar os seus conhecimentos e os seus saberes fora, têm uma boa formação. Mas as condições de trabalho que a Universidade tem criado não permitem que essas pessoas se dediquem inteiramente ao Departamento para o fazer crescer, ou se dediquem inteiramente ao ensino das disciplinas. Portanto, são pessoas que dividem a sua vida entre dar uma aula e em seguida vão para outra universidade para dar mais uma ou duas cadeiras e poder aumentar o seu orçamento familiar, poderem ter mais renda. Ou então fazem uma outra atividade, alguns até criam as suas próprias empresas porque as condições de trabalho na Universidade não são aliciantes, não compensam em relação ao esforço que é desenvolvido. Alguns dos estudantes que nós formamos estavam ligados a determinados locais de trabalho, e a licenciatura em Antropologia permitiu talvez um aumento salarial, porque a formação tem o canudo, mas depois não se empenharam muito em termos de fortalecer o próprio Departamento, o ensino de Antropologia em Moçambique.

Outro grande problema é que, entre os antropólogos, foi criada uma Associação de Antropologia que tentava de fato agregar antropólogos de todas as Universidades. Mas a criação desta Associação não trouxe uma maior interação entre os antropólogos, uma organização conjunta de trabaIhos, de conferências, de debate para discutir questões ou tendências mais atuais da Antropologia, de aprofundar o conhecimento entre as pessoas, desenvolver conjuntamente determinado tipo de pesquisa. Eu sinto que há uma dispersão ainda por parte dos antropólogos e não há a possibilidade de uma forma conjunta para enriquecer o debate sobre qual é o papel que a Antropologia pode ter em Moçambique hoje, no futuro e desenvolver a própria Antropologia. Na Associação dos Economistas, por exemplo, vemos frequentemente que há debates que permitem que haja esta interação entre eles, que se conheçam, porque há uma geração mais velha, outra mais nova. Mas em relação a Antropologia não há. Isto é um pouco como eu vejo. Mas como nos últimos anos estou um pouco afastada, vou de vez em quando, (risos), penso que o Hélder deve conhecer melhor do que eu (risos), o que se passa lá no DAA. 
Eu fiquei pensando na riqueza da sua trajetória de vida, pois está inserida na história contemporânea do país: o período colonial e a luta anticolonial você viveu de criança. Mas certamente isso teve um impacto na sua forma de ver o mundo. Como é para você ser uma historiadora, uma antropóloga e ao mesmo tempo uma protagonista dessa história, como uma intelectual que também é comprometida e engajada numa luta concreta?

AL | Eu felizmente tive a oportunidade de poder estar em diferentes espaços, durante muito tempo ligada a academia como professora, formadora de novas gerações, em períodos muito, muito difíceis de funcionamento do próprio DAA e de luta no dia-a-dia para conseguir avançar com os cursos, porque realmente tínhamos muita carência de docentes e era um desafio diário conseguir. Penso que contribuí, juntamente com outros colegas que lá estavam, alguns muito mais novos, mas que se dedicavam bastante à causa da Antropologia. Depois estive em outros espaços, também por razões de poder educar os meus filhos, dar a possibilidade de ter um estudo de maior qualidade, o que me levou a trabalhar como consultora e assessora técnica de gênero no Ministério da Mulher (agora chamado de Gênero), e como assessora técnica do UNEFPA (United Nations Population Fund) ${ }^{7}$. Acompanhei a criação da primeira Direção Nacional da Mulher (DNM) e do primeiro Ministério da Mulher, num projeto de empoderamento. Este projeto promovia a capacitação institucional do Ministério, da DNM e o fortalecimento de Associações de Mulheres nas comunidades. Tive a oportunidade de fazer formações sobre questões de gênero ao nível da base, numa altura que pouco se falava e pouco se conhecia sobre esta mesma problemática. Foi um desafio conhecer e transmitir uma série de legislação e políticas públicas para as mulheres ao nível destas comunidades onde trabalhávamos e ao nível de técnicos nos diferentes Ministérios. Também fazia formação sobre questões de integração de gênero nos Ministérios, sobre orçamento e planejamento na ótica de gênero. Continuando na academia, estava no setor público e também na formação das próprias comunidades. Posso me considerar uma pessoa, de certa maneira, privilegiada: por um lado o conhecimento acadêmico me permitia fazer uma reflexão, me permitia ter as metodologias e as formas de comunicação para as comunidades, por outro, poder de fato, em conjunto com essas mesmas pessoas, refletir sobre o seu dia-a-dia, experiências, vivências diárias. Penso que foi uma combinação muito boa de na academia aprofundar os conhecimentos teóricos para poder lecionar, e dar as ferramentas ou instrumentos para refletir sobre uma realidade que tinha que discutir com as pessoas com quem eu trabaIhava, a formação de quadros do Ministério, de outros setores e também das mulheres das Associações. 


\section{E como é que surge a WLSA na sua trajetória?}

AL | A WLSA surgiu em 1989 dentro da Universidade, então suas fundadoras são acadêmicas: eu, a Ximena Andrade, a Maria José Artur, a Conceição Osório, a Isabel Casimiro, a Irene Afonso (jurista), a Terezinha da Silva. Foi um convite às mulheres que se dedicavam, em termos de investigação e de docência, às questões de gênero para, a nível destes países, integrarem as diferentes WLSA's. Então durante muito tempo, como membro fundadora da WLSA, participava um pouco à distância. Houve uns três anos que participei em pesquisas como investigadora associada, porque nessa altura ainda estava ligada ao DAA. Participei da pesquisa cuja publicação é "Famílias em contextos de mudança»e numa pesquisa como sobre direito a alimentos. Depois passei a fazer parte dos órgãos sociais, como presidente da mesa da Assembleia Geral e quando me reformei na Universidade, em 2012, recebi o convite para ser membro do staff da WLSA, que de forma direta ou indireta sempre fez parte nos últimos anos da minha vida. Acompanhando a pesquisa, muitas vezes era convidada também para participar em conferências internacionais representando a WLSA, como membro - quer dos órgãos sociais ou como fundadora. Também colaborei durante seis anos com artigos para o Boletim da WLSA, "Outras Vozes". Atualmente sou coordenadora na área de formação.

\section{Como foram os processos de reforma curricular que ocorreram no DAA durante o período em que foi professora, ou que tenha tomado conhecimento. Houve al- guma reforma em termos de estrutura do curso e o que demandou essa reforma?}

AL $\mid$ Houve um processo de reforma em termos curriculares, numa altura em que toda a Universidade teve a necessidade de reduzir o período das licenciaturas de 5 anos para 3 anos. Teve muita contestação, mas nós fomos obrigados a reduziro curso de Antropologia, tentando adaptar a esta demanda, que felizmente não foi avante. Este é o que eu me recordo. Houve um período que realmente nós tivemos que fundir algumas cadeiras, retirar outras, colocar outras. Depois ver se poderíamos ter créditos em outros cursos. Foi um processo muito conturbado da vida da Universidade, naturalmente do próprio DAA. Também surgiu a necessidade de adaptarmos o curso às necessidades do mercado de trabalho em termos de Antropologia e darmos mais ênfase àquela formação que permitia a saída para o mercado de trabalho, que fosse mais apropriada e pudesse de certa maneira incentivar também os futuros antropólogos. Foram introduzidas cadeiras ligadas, por exemplo, à Antropologia da Saúde e à Antropologia Aplicada ao Desenvolvimento. Depois surgiu nos últimos anos a necessidade de termos um Mestrado em Antropologia, que eu acho que conhece melhor do que eu (risos). 
A minha última pergunta é sobre a Ana mulher, esposa, avó. Que nos falasse um pouquinho sobre como foi conciliar essa rica e intensa trajetória profissional, acadêmica e ativista com as demandas familiares, domésticas?

AL | É muito difícil (risos), sobretudo, no período ligado ao doutoramento. Eu fiz num sistema sanduíche: ficava meses aqui em Moçambique, depois, tinha que ir à Portugal. Durante muitos meses fiz a parte letiva quando meus filhos eram bem pequenos (o mais velho tinha 7 anos e a menina tinha 4). Tive bastante apoio da minha mãe se não seria muito...seria difícil. Tive muito apoio do meu marido, que também ajudava a tomar conta das crianças e sempre dizia: "tens que sair, não há problemas, eu tomo conta da casa e das crianças". Mas, havia períodos duros em que eu tinha que escrever e a minha filha abria a porta e dizia "quando é que tu acabas essa tua tese, nunca mais? " (Risos). Então é um período difícil. Às vezes ia a Portugal para discutir com o supervisor os capítulos, corrigir e melhorar, no dia que regressava era assim um rol de problemas (risos).

\section{E era máquina de escrever ainda no seu tempo ou já se usava o computador?}

AL | Era computador, naqueles programas muito arcaicos, mas era computador. Mas o meu supervisor, o Hélder deve conhecer, o José Fialho Feliciano, é uma pessoa já de uma certa idade e nem sei se agora tem internet (risos). Durante muito tempo eu tinha que levar ou mandar pelo correio os escritos da minha tese para ele ver e corrigir, porque pela internet não valia a pena: ele não ligava (risos). Ele era uma daquelas pessoas - e acho que continua -para quem as tecnologias não eram com ele. Então foi duro, mas pronto, felizmente tudo correu bem, mas foram cinco anos muito, muito, muito difíceis. Depois voltei e mais uma vez era preciso dividir as tarefas domésticas com esta professora, com assessora. Era esta que me dava a possibilidade de pagar os estudos do filho que estudou no Brasil, e tinha que todos os meses complementar as bolsas. Era uma situação difícil, mas acho que depois valeu a pena (risos). Como avó estou muito contente, gosto muito, tenho quatro netas, só meninas (risos), mas, são muito queridas. Dão-nos muito, muito prazer e é bom recordar, tomar conta, dar banho, lavar fraldas etc. (risos), dá muita alegria. Muitas brincadeiras e expressões das crianças que enchem o meu dia-a-dia, gosto de ser avó (risos).

Agradecemos imensamente a disponibilidade e por mais uma vez abrir-nos as portas e dispensar parte do tempo, que como sabemos nos dias que correm não é muito fácil. Esperamos contar sempre que precisarmos com o apoio da professora para as próximas invenções. 
Vera Gasparetto realiza pós-doutorado no Programa de Pós-Graduação Interdisciplinar em Ciências Humanas (PPCICH), na área de Concentração Estudos de Cênero (ECE), na Universidade Federal de Santa Catarina (Bolsista CAPES/PNPD). Doutorou-se em 2019 no PPGICH, na área de concentração ECE. Defendeu a tese intitulada "CORREDOR DE SABERES: Vavasati Vantinhenha (Mulheres Heroínas) e redes de mulheres e feministas em Moçambique".

Helder Pires Amâncio Doutorando em Antropologia Social na Universidade Federal de Santa Catarina com Projeto de Pesquisa "História e Ensino da Antropologia em Moçambique". Mestre na mesma área e Universidade com dissertação intitulada "Da casa à escola e vice-versa: Experiências de inicio escolar de crianças em Maputo", (2016). Graduado em Antropologia pela Universidade Eduardo Mondlane com trabalho de conclusão de curso "A escola como mercado de trocas: um estudo sobre processos de construção de sucesso numa escola na cidade de Maputo" (2013).

\section{REFERÊNCIAS BIBLIOGRÁFICAS}

MUDIUE, Armando Meque. 2005. A constituição de família nas comunidades de Vacopi. Maputo, Editora Escolar.

ROSEIRO, António Henrique Rodrigues. 2013. Símbolos e práticas culturais dos Makonde. Coimbra, Tese de Doutorado em Antropologia Social e Cultural, Universidade de Coimbra. 